\title{
Research Notes \\ Opposites Do Not Attract: The Impact of Domestic Institutions, Power, and Prior Commitments on Alignment Choices
}

\author{
SuZANNe Werner \\ Emory University \\ AND \\ Douglas Lemke \\ University of Michigan
}

\begin{abstract}
States that choose to involve themselves in an ongoing dispute do so by choosing to align with or against one of the original disputants. What factors lead states to prefer to help one side over the other? We consider the effect of the disputants' power, political and economic institutional similarities between each disputant and the aligning state, and formal alliance commitments between each disputant and the aligning state on these alignment choices. We evaluate these expectations empirically by examining the alignment choices of states that joined with one side or another in a Militarized Interstate Dispute during the period of 1816 to 1986. The results indicate that regardless of regime type, institutional similarities matter to the aligning state's decision. We also find that power concerns matter only to autocracies; democracies do not seem to base their alignment choices on the power of the sides in the dispute. Finally, the evidence indicates that the alignment choices of democracies cannot be anticipated by their prior alliance commitments, although the alignment choices of autocracies can. These results suggest interesting implications for research on the democratic peace, the determinants of threat in the international system, and the impact of selection effects. The consistent empirical evidence that institutional similarity affects alignment decisions also increases our confidence that future investigations of institutional similarity generally, rather than an exclusive focus on joint democracy, will prove fruitful.
\end{abstract}

The foreign policy choices of states can provide important information about the preferences of state leaders. Few foreign policy choices are as revealing as the decision to align with one side over another in an ongoing dispute. Even more than a formal alliance, actually siding with a disputant reveals a clear preference for one

Authors' note: The authors thank the editors and reviewers of ISQ for their helpful comments. Data are available upon request from Werner. Werner's contribution was supported in part by the University Research Committee of Emory University.

(C) 1997 International Studies Association.

Published by Blackwell Publishers, 350 Main Street, Malden, MA 02148, USA, and 108 Cowley Road, Oxford OX4 1JF, UK. 
state over another. Whereas a formal alliance often promises some form of support against some unspecified opponent, the decision to assist a disputant in an ongoing dispute actually delivers aid against a specific opponent. Our goal is to identify those factors that affect such alignment choices of states. By doing so, we hope not only to understand better this specific foreign policy choice, but to understand better those factors that lead decision makers to prefer one state over another.

Our empirical evaluation of the alignment decisions of states that joined ongoing Militarized Interstate Disputes between 1816 and 1986 reveals that similarities in the political and economic institutions of states are an important determinant of alignment behavior and that such similarities were important regardless of the aligning state's regime type. The investigation also demonstrates that while the power of the original disputants and former alliance commitments between the aligning state and an original disputant generally affected alignment behavior, these effects held only for aligning autocracies. These results suggest interesting implications for the democratic peace, the realist and neorealist paradigm, and the growing literature on selection effects.

\section{The Alignment Choices of States}

Alignment choices remain a relatively understudied phenomenon. Several literatures, however, highlight factors that might help to explain these decisions. Since the decision to join a war is closely related to the decision to align with a particular disputant, the war diffusion literature should provide a solid foundation for inquiry into alignment behavior. Explaining why some wars spread has received considerable attention (Davis, Duncan, and Siverson, 1978; Most and Starr, 1980; Yamamoto and Bremer, 1980; Bremer, 1982; Levy, 1982; Siverson and Starr, 1990, 1991). The war diffusion literature can be viewed as revolving around two principal concepts identified by Siverson and Starr (1990, 1991): the opportunity to get involved in and affect dispute outcomes, and the willingness to help or hinder one of the disputants. Although there are obvious connections between joining and alignment decisions, factors affecting a state's opportunity to join seem less relevant to alignment behavior as they identify characteristics of the dispute, rather than characteristics of the disputants, which make intervention worthwhile. Siverson and Starr (1991), for instance, demonstrate that contiguous third parties are significantly more likely to join a war than distant states as their proximity affords them the opportunity to become involved. Altfeld and Bueno de Mesquita (1979) similarly argue that a state is unlikely to join a war unless it has sufficient resources relative to the primary disputants to affect the outcome. While proximity and capability clearly affect the likelihood of involvement, it is not clear why either factor should affect alignment behavior as neither factor indicates any preference over the actual outcome of the dispute.

In contrast, a factor that affects the willingness of a prospective third party may be relevant to alignment behavior as it may identify aspects of the disputants that motivate the joiner. ${ }^{1}$ Willingness, unlike opportunity, focuses on why a state gets involved rather than if it can. Alliance commitments between a disputant and a potential third party are one such factor identified as central to the potential for war diffusion (Altfeld and Bueno de Mesquita, 1979; Siverson and King, 1979;

\footnotetext{
${ }^{1}$ Not all factors affecting willingness relate to characteristics of the disputants. Yamamoto and Bremer (1980) demonstrate that the probability of a major power entering an ongoing war depends on the prior decisions of other major powers. Major powers are more likely to enter a war if other major powers have already joined, but are less likely to enter if no other major power has yet joined the war. Although major power involvement seems to affect the willingness of other major powers, this condition does not bear on characteristics of the disputants and thus does not appear relevant to alignment choices.
} 
Siverson and Starr, 1991). Alliance commitments will likely affect alignment behavior as well as the potential for diffusion (joining behavior) because such commitments indicate interest in one of the disputants. There are thus strong reasons to anticipate that formal alliance commitments affect not only the decision to join, but also the decision to align with one side. Specifically, we expect that a third party that joins a dispute will be more likely to help the side to which it has made a previous commitment via a formal alliance.

While studies of war diffusion focus specifically on a third party's potential involvement in a dispute, realists and neorealists have focused more generally on the expected behavior of states in a threatening environment. Since realists and neorealists expect that states will often form alliances with other states when threatened, this body of work can inform our expectations of alignment choices. Within the realist tradition, power considerations are thought to dominate such choices, especially in times of crises. Realists and neorealists argue that power plays the predominant role in foreign policy decisions because states fear that the powerful can eliminate the weak (Morgenthau, 1948; Waltz, 1979). This fear of conquest undergirds the realist and neorealist belief about which state characteristic is important-power-and conditions expectations about state behavior-balancing against the strong to prevent the weak's elimination. ${ }^{2}$

While recent revisions of realist logic do not veer from the traditional focus on power as the motivation for alignments, ${ }^{3}$ some scholars currently argue that states may also bandwagon with, as well as balance against, the stronger state. States may bandwagon to placate the more powerful state (Walt, 1987) or to "obtain values coveted" (Schweller, 1994). Evaluation of the historical record has yet to resolve the debate. ${ }^{4}$ While realism may not provide definitive expectations about whether joining states will choose the weak or the strong, there is clear agreement that the distribution of power between the original disputants will play an important role in such alignment choices.

Although neither the diffusion nor the realist literature suggests that domestic institutions play an important role in the alignment choices of states, there are several arguments that suggest the contrary. For instance, the normative explanation for the democratic peace posits that the democratic process fosters norms of peaceful dispute resolution (Dixon, 1993, 1994; Maoz and Russett, 1993; Russett, 1993). While the law-governed behavior of their domestic setting encourages democratic leaders to respect international laws, the domestic political experience of compromise and nonviolent competition encourages democratic leaders to seek out alternative means of dispute resolution when faced with an international crisis. This enables democracies to avoid violent conflict with each other.

If democratic dyads experience less conflict than expected as a result of shared norms of compromise, we might anticipate that they also enjoy more cooperation. Siverson and Emmons (1991) test this argument by evaluating the tendency for democracies to form formal alliances with other democracies. They find that

\footnotetext{
${ }^{2}$ Morgenthau (1948:131), justifying the importance of a balance-of-power policy, argues that "[t]he other function which a successful balance of power fulfills under these conditions is to insure the freedom of one nation from domination by the other." Grieco (1988:487) similarly argues that states fear conquest by other states. He writes that "[r]ealism's identification of the relative gains problem for cooperation is based on its insight that states in anarchy fear for their survival as independent actors." Waltz (1986:102) likewise writes that "[i]n any self-help system, units worry about their survival, and the worry conditions their behavior."

${ }^{3}$ Walt (1987), however, does argue that the degree of threat posed by another state depends not only on its aggregate power, but also on its geographic proximity, offensive capability, and its perceived aggressiveness. Geographic proximity and offensive capability are still indicators of a state's ability to enforce its will on another, and therefore at least two thirds of Walt's threat differs little from the traditional power focus.

${ }^{4}$ While Walt (1987) notes that bandwagoning is possible, he argues that balancing predominates. Others suggest that bandwagoning has been the more common behavior (Kaufman, 1992; Schweller, 1994).
} 
democracies do tend to form alliances with each other more than would be expected by chance alone from 1920 to 1965. Although Siverson and Emmons's study examines the formation of formal alliances, rather than actual alignment choices, their study creates expectations that democratic states will be predisposed to side with fellow democracies in crises. According to this argument, democratic states would align with fellow democracies because they share the same objectives and norms. ${ }^{5}$

While the democratic peace literature can be read to suggest that democratic states particularly will have a proclivity to align with each other, there are also several reasons to expect that similar domestic institutions more generally will lead all states to favor those with more rather than less similar domestic institutions. Hermann and Kegley (1995), for instance, offer a psychological explanation of the democratic peace which assumes that perceptions of other states will be colored by the composition of one's ingroup and outgroup. Foreign policy decisions are affected by these perceptions and will, as a result, be biased toward those within the ingroup and against those without. We might expect, then, that states will tend to align with those states within their ingroup and against those without. If similarity in political system, or similarity in domestic institutions generally, distinguish ingroups from outgroups, then similar states, whether similar democracies or similar autocracies, will tend to align with each other against those with different domestic institutions.

An interest-based theory concludes similarly (Werner and Lemke, 1996). Domestic institutions are relevant to foreign policy choices because they can affect not only the process of and constraints on decision making, but also the distribution of resources in society. Knight (1992) argues, for instance, that while different institutions may accomplish the same ends, like arranging economic exchange, ordering social relations, or managing political life, the particular form of the institution determines the distributional consequences. Different institutions can achieve similar objectives, but the identity of the beneficiaries will differ.

Since leaders often either choose the institutional structure or are chosen by it, a leader's interests will be closely tied to the preservation of the institutional structure of his state. ${ }^{6}$ States that challenge the maintenance and stability of the institutional structure of a leader's state will appear particularly threatening to the leader. ${ }^{7}$ States with different institutions should be particularly threatening because they can increase the costs of enforcing the state's particular set of institutions. If the costs of enforcement are lowest when there exists a common consensus of either the

\footnotetext{
5 One exception arises from the alliance choices of democracies in the years immediately preceding WWII. In these years, there were fewer alliances between democracies than one would expect by chance alone. This might suggest that when security issues become paramount, as in an actual dispute or crisis, similar norms and policy orientations might matter less to the states. If so, we might expect that in this study, which focuses on the alignment behavior of states in the midst of a dispute, democratic states would be no more likely to join the democratic side than the autocratic side. Siverson and Emmons (1991) identify another possible explanation, however, which does not suggest that domestic institutions become less important in times of crisis. That is, the marked decrease in alliances between democracies might reflect the numerous regime changes which occurred during the inter-war years. In this case, alliances between democracies declined because an alliance between formally democratic states was not officially revoked when one or both states underwent an authoritarian regime change. Considering the actual alignment choices of states in the midst of a dispute, rather than the formation of formal alliances at some pre-dispute time, will help to clarify whether the cooperative tendencies expected between democracies occur only in the limited instances where security concerns do not predominate, as realists and neorealists might expect, or if relations between democracies are special regardless of the security situation.

${ }^{6}$ Lake (1996:5-6, italics added) defines security "as the ability to consume, invest, or otherwise use national wealth as a polity sees fit." The two essential national freedoms then are "the freedom to possess wealth, traditionally associated with the territorial integrity of the nation-state, and the freedom to choose its own form of rule, embodied in constitutional independence and a defining characteristic of sovereignty." We likewise concur that the ability to determine the institutional structure of the state is of primary interest to the leader.

${ }^{7}$ Werner (1996), for instance, demonstrates that a war participant is much more likely to endure a foreign imposed regime change if it and its opponent have different domestic institutions.
} 
inevitability or the legitimacy of a particular set of institutions, then examples of alternative means of distributing the wealth of society should increase such enforcement costs by altering popular or elite expectations about expected or acceptable patterns of distribution. As the common consensus breaks down and challenges to the institutions increase, the costs of preserving a particular institutional arrangement may become prohibitive. ${ }^{8}$ States with more efficient institutions may also force leaders who benefit from their less efficient but distributionally advantageous institutional arrangements to adapt in order to remain competitive in the international system. While the adaptation might increase aggregate social returns, it might do so by reducing the rents realized by the leader (North, 1981; Lake, 1992). Finally, a leader might recognize that states with different institutional structures may actively promote the interests of the leader's internal challengers. In short, if leaders attempt to maintain their position of power, not for the position itself, but for the distributional advantages that accrue from the office, then leaders and their cohorts will find states with differing institutional structures particularly threatening. ${ }^{9}$ Alignment choices then should reflect the leader's preference for institutionally similar states which buttress the leader's hold on power, over institutionally dissimilar states which may challenge the legitimacy and security of his position of authority.

There are both psychological and interest-based reasons why differences in domestic institutions should affect the alignment choices of states. Both perspectives associate differences with threat perception. The empirical evidence will suggest whether domestic institutions matter to alignment behavior and whether democratic states alone enjoy a special relationship, as democratic peace theorists might anticipate, or if states with similar domestic institutions generally tend to support each other against those with different domestic institutions.

We have identified several factors likely to affect alignment behavior. If states find others threatening because of their capabilities, as the realists and neorealists argue, then we will find that alignment choices depend on the power of the original disputants. Psychological and interest-based explanations suggest, in contrast, that states will assess the potential threat or appeal of another based not on their power, but on the similarity of their domestic institutions. If these arguments are true, third parties will align with the institutionally similar disputant against the more threatening, dissimilar disputant. Alignment behavior need not be motivated by fear, however. If democracies share similar means of conflict resolution, then we will find them aligning with other democracies in times of crises. Likewise, past research leads us to expect that states will align with an allied disputant rather than with a disputant with which it has made no previous defensive commitment.

\section{Empirical Evaluation}

Do domestic institutions affect the alignment choices of states, or do power concerns alone dominate this decision? Do democratic states alone share a special relationship, or do all states with similar domestic institutions generally ban together? Finally, do previous promises to aid affect the actual alignment decisions made, or

\footnotetext{
8 The empirical tendency noted by several international and comparative scholars for domestic changes to diffuse to neighboring or regional states provides some support for this expectation (Lutz, 1989; Ray, 1989; Kegley and Raymond, 1990; Huntington, 1991; Starr, 1991).

9 This focus on the specific interests of the leader, rather than those of the state, is not new. Although traditionally the interests of the state and those of its leader were considered identical, increasingly scholars have noted that leaders may have interests of their own which may differ from "state interests." Bueno de Mesquita, Siverson, and Woller (1992) and Bueno de Mesquita and Siverson (1995) assume that political survival is the leader's primary motivation. Diversionary theorists similarly assume that many foreign policy decisions are motivated by a leader's desire for increased popularity or decreased domestic discontent (Levy, 1989; Morgan and Bickers, 1992).
} 
are crisis decisions unaffected by such prior commitments? We offer preliminary empirical evidence to address these questions by examining alignment choices in ongoing Militarized Interstate Disputes. The temporal domain of our investigation is the period 1816 to 1986 . We utilize the revised and updated Correlates of War Militarized Interstate Dispute Data Set to identify instances where states have expressed their preference for one state or set of states over another state or set of states. ${ }^{10}$ This revised data set identifies not only each participant in the dispute, but also the day on which they became involved. Consequently, we are able to determine which states were initial disputants and which states subsequently joined the dispute.

We are interested in those states that participated in a dispute but were not involved on the first day the dispute began. We look only at those states that actually participated in the dispute because we believe it reasonable to assume that once a dispute begins, each state in the system "decides" which side it would align with if it were to join the dispute and then decides whether to actually enter the dispute based on its opportunity to act and contribute. The decision to favor one side or another and the decision to enter then are independent and based largely on different factors. If the decision to favor one side and to join the dispute are linked, however, the decision to look only at states that actually participated rather than at the population of potential participants will introduce some bias into our results. Given the difficulty of identifying the population of "potential participants," we believe such a simplification is reasonable, although our results must be interpreted with some caution.

A state (j) chooses to align with either Side A or Side B. Side A and Side B include all those states that were participating on that side as of the date the aligning state, $\mathrm{j}$, became involved. As a result, if several states entered a dispute at different times, those that entered later will be aligning not only with the initial disputants, but also with all those that became involved prior to their participation. This is reasonable because the character of a side, and a state's decision to favor one side over another, might change as other states become involved.

The literatures reviewed create very different expectations about the motivations behind these alignment decisions. The empirical test should reveal whether states base their alignment decisions on power concerns, institutional similarities, or prior commitments. It should also reveal which institutions matter. We operationalize these variables using standard data sets. To estimate the power of Side A and Side $\mathrm{B}$, we utilize the Correlates of War composite capability index. We measure the power of each side as the sum of the power of each state on that side. According to traditional balancing expectations, a state will be more likely to align with Side A as Side A's power decreases and Side B's power increases.

To evaluate expectations of the impact of domestic institutions, we estimate the similarity between the political and economic institutions of $\mathrm{j}$ and Sides A and B.11 The political institutions of a state can vary on a number of dimensions. One key dimension, however, is the representativeness of a state's polity. The institutional democracy variable within the Polity II data set indicates, according to Gurr, Jaggers, and Moore (1989:36-9), the competitiveness of political participation, the openness and competitiveness of executive recruitment, and the constraints on the chief executive. An 11-point scale is constructed for the level of democracy and serves as our measure of a state's political institutions. ${ }^{12}$

10 The original MID data set is described in Gochman and Maoz (1984).

${ }^{11}$ We also examine whether democratic states alone exhibit special behavior by dividing the data set so that we can examine the alignment decisions of democratic and autocratic aligning states separately.

12 Gurr, Jaggers, and Moore (1990) and Jaggers (1992) provide additional information on these variables. 
The economic institutions of a state can likewise vary on numerous dimensions. The government's involvement in the economy, however, does indicate one key dimension over which such institutions vary. The scope variable within the Polity II data set indicates "the extent to which all levels of government . . . attempt to regulate and organize the economic and social lives of the citizens and subjects of the state" (Gurr, Jaggers, and Moore, 1989:21). The 9-point scope scale serves as our indicator of a state's economic institutions.

We construct four variables from this information about state political and economic institutions. The first and second variables reflect the difference between the political institutions of $\mathrm{j}$ and Side $\mathrm{A}$ and of $\mathrm{j}$ and Side B, respectively, measured by the absolute difference in their institutionalized democracy scores. The third and fourth variables reflect the difference between the economic institutions of $j$ and Side A and of $\mathrm{j}$ and Side B, respectively, measured by the absolute difference in their scope scores. If Side A or B had more than one member at the time $\mathrm{j}$ was choosing which side to favor, the institutionalized democracy and scope score for the side were equal to the average institutionalized democracy and scope scores for the states that comprised the side. If regime type alone affects foreign policy behavior, then the similarity in economic institutions should not matter. If, in contrast, $\mathrm{j}$ evaluates the threat posed by Sides A and B by the degree to which their institutions are similar, as is suggested by both the psychological expectations of Hermann and Kegley (1995) and the interest-based expectations of Werner and Lemke (1996), then both the political and economic variables will affect alignment behavior. State $\mathrm{j}$ will be more likely to align with Side A as the difference between its political and economic institutions and those of Side A decrease, and as the difference between its institutions and those of Side B increase. The test should reveal whether domestic institutions affect foreign policy decisions and which domestic institutions matter.

To estimate the extent to which $\mathrm{j}$ had an alliance commitment with each disputant, we created two variables, one that identified the proportion of states on Side A with which $\mathrm{j}$ had a defense pact and another that indicated the proportion of states on Side B with which $\mathrm{j}$ had a defense pact. Each variable then varies between zero and one, indicating whether $\mathrm{j}$ has a defense pact with none, some, or all of the states on a particular side. The Correlates of War Formal Alliance project identifies the disputants with which $\mathrm{j}$ had a defense pact. ${ }^{13}$ We considered only the existence of a defense pact, rather than the existence of an entente or a neutrality pact, because only a defense pact indicates a commitment to aid another in the case of an attack. ${ }^{14}$

We estimate the following logistic regression model as the decision to join Side A or not:

$$
\begin{gathered}
\text { State } \left.\mathrm{j} \text { Aligns with Side } \mathrm{A}=\beta_{0}+\beta_{1} \text { (Diff. Regime of } \mathrm{J} \& \mathrm{~A}\right)+\beta_{2} \\
\text { (Diff. Regime of } \mathrm{J} \& \mathrm{~B})+\beta_{3}\left(\text { Diff. Economies of J\&A) }+\beta_{4}\right. \\
\text { (Diff. Economies of J\&B) } \left.+\beta_{5} \text { (Power of } \mathrm{A}\right)+ \\
\beta_{6} \text { (Power of B) }+\beta_{7} \text { (Defense Pact between J\&A) }+\beta_{8} \\
\text { (Defense Pact between J\&B) }+\varepsilon
\end{gathered}
$$

\footnotetext{
13 See Singer and Small (1966) and Small and Singer (1969) for a description of the project.

${ }^{14}$ We also ran the model with the alliance variables operationalized as the proportion of states on Side A with which $\mathrm{j}$ has either a defense pact, an entente (a commitment to consult), or a neutrality pact (a commitment to remain uninvolved). The results remained virtually unchanged. The only significant change was that when we considered only those cases where the aligning state was a democracy, the political institutional variables no longer met conventional standards of statistical significance when the alliance variable was operationalized by this broader criteria. This is not surprising since, as would be anticipated by the analysis of Siverson and Emmons (1991), there is a significant negative correlation between differences in the political institutions of $\mathrm{j}$ and Sides A and B and the existence of a broad alliance commitment.
} 
The dependent variable is equal to one if the state aligns with Side A and zero if it aligns with Side B. If institutional similarities affect alignment behavior as anticipated by Hermann and Kegley (1995) and Werner and Lemke (1996), then $\beta_{1}$ and $\beta_{3}$ will be negative, implying that as the difference between the institutions of $\mathrm{j}$ and Side A increases, $\mathrm{j}$ is less likely to align with Side A. In this case, we would also expect that $\beta_{2}$ and $\beta_{4}$ will be positive, suggesting that as the difference between j's institutions and those of Side B increases, $j$ will be more likely to align with Side A over Side B. We anticipate that most realists and neorealists would expect $\beta_{5}$ to be negative and $\beta_{6}$ to be positive, implying that $\mathrm{j}$ will be more likely to align with a side as that side gets weaker. Finally, we would expect according to the war diffusion literature, that former promises will be honored implying that $\beta_{7}$ will be positive while $\beta_{8}$ is negative.

Table 1 reports the results of the logistic regression model and the classification table produced. These results are very encouraging and increase our confidence that we have identified factors relevant to the alignment decision. Conventional realist expectations that the importance of domestic institutions will decline dramatically in crises do not appear to be warranted. The institutional variables all have the expected sign and easily meet traditional standards of significance. The evidence indicates that an aligning state is more likely to align with Side A as its political and economic institutions become more similar to Side A and less so with Side B, but more likely to align with Side B as its institutions become less similar to Side A and more similar to Side B. In contrast, while significant, the relationships for the power variables are not in the direction that we believe most realists and neorealists would expect. While there is a relationship between each side's power and j's decision, the evidence indicates that $\mathrm{j}$ is more likely to align with Side A as A's power increases, but less likely to align with Side A as B's power increases. Rather than balancing against the stronger side, the evidence suggests that states tend to align with them and thus supports the expectations of the revisionist realists (Kaufman, 1992; Schweller, 1994). Finally, as would be anticipated by the war diffusion literature, a prior promise to aid increases the likelihood that $j$ will align with that side when called upon. Alliances therefore indicate not only which states are more likely to join an ongoing dispute (Siverson and Starr, 1991), but also which side will receive the benefit of their aid.

The classification table provides additional information. The model's overall predictive ability is 74.55 percent correct, which exceeds the 50.13 percent correct predictive ability of the modal category (align with Side A). The model provides a proportional reduction in error of 49 percent from the naive model which assumes that the modal category always occurs. The pseudo $\mathrm{R}^{2}$ of .52, calculated according to Aldrich and Nelson's (1984) technique and with Hagle and Mitchell's (1992) multiplier, indicates that the model provides a reasonable fit for the data.

As an additional indication of the fit of the model, we constructed a calibration table. A calibration table compares the predicted probabilities of an event with the proportion of cases for which the event actually occurred. If the model were perfect, we would expect that the predicted probability of an event and the proportion of cases for which the event occurred would be equal, creating an upward-sloping 45 -degree line and a calibration index score of 0.15 A downward-sloping diagonal line and a calibration index score of 1 , on the other hand, would indicate the worst possible level of calibration. The calibration table we constructed suggests that the

15 The calibration index score, CI, is calculated in the following manner where $\mathrm{N}$ represents the total number of observations, $\mathrm{N}_{\mathrm{j}}$ indicates the number of cases in a predicted category, and $\mathrm{d}_{\mathrm{j}}$ represents the proportion of times the target event actually occurred when a particular proportion was predicted, $\mathrm{f}_{\mathrm{j}}: \mathrm{CI}=\Sigma\left(\mathrm{CI}_{\mathrm{j}} / \mathrm{N}\right), \mathrm{CI}_{\mathrm{j}}=\mathrm{N}_{\mathrm{j}}\left(\mathrm{f}_{\mathrm{j}}-\mathrm{d}_{\mathrm{j}}\right)$. See Yates (1990) for additional information. 
TABle 1. The Effects of Political and Economic Institutional Differences, Power Relations, and Formal Alliance Ties on a Joiner's Decision to Align with Side A

\begin{tabular}{|c|c|c|c|c|}
\hline Variable & Coefficient & $\begin{array}{l}\text { Standard } \\
\text { Error }\end{array}$ & $\begin{array}{c}\text { Range of } \\
\text { Variable }\end{array}$ & $\begin{array}{l}\text { Change in } \\
\text { Probability } \\
\text { of j Aligning } \\
\text { with Side A }\end{array}$ \\
\hline Constant & -0.4174 & 0.2978 & & \\
\hline Diff. economies of $\mathrm{j} \& \mathrm{~A}$ & -0.3490 & $0.0748 * * *$ & $0-8$ & -.5322 \\
\hline Diff. economies of $\mathrm{j} \& \mathrm{~B}$ & 0.2845 & $0.0776 * * *$ & $0-8$ & .4997 \\
\hline Diff. regime of $\mathrm{j} \& \mathrm{~A}$ & -0.1630 & $0.0434 * * *$ & $0-10$ & -.3740 \\
\hline Diff. regime of $\mathrm{j} \& \mathrm{~B}$ & 0.1690 & $0.0442 * * *$ & $0-10$ & .3987 \\
\hline Power of A & 6.2624 & $1.2545 * * *$ & $.0001-.8216$ & .6903 \\
\hline Power of B & -3.2863 & $1.0978 * *$ & $.00001-.6653$ & -.4222 \\
\hline Defense pact between j \& A & 2.0764 & $0.4627 * * *$ & $0-1$ & .4140 \\
\hline Defense pact between j \& B & -1.4041 & $0.5438 * *$ & $0-1$ & -.2852 \\
\hline
\end{tabular}

$* * *=\mathrm{p} \leq 0.001 ; * *=\mathrm{p} \leq 0.01 ; *=\mathrm{p} \leq 0.05$

Calibration index $=0.0195$

Predicted Behavior of Joining State

Actual Behavior of

Join State B Join State A

Joining State Join State B Join State

Join State B $\quad 152 \quad 40$

Join State A $\quad 58 \quad 135$

Percentage of correct predictions $=74.55 ;$ null model $=50.13 ; \mathrm{N}=385$

Model chi-square $=165.294$, d.f. $=8$, significance $<0.0001$, pseudo $\mathrm{R}^{2}=.52$

Significance levels based on $\mathrm{X}^{2}$ calculations

fit of the model is very good. The predicted probability is a good indication of the proportion of cases for which $\mathrm{j}$ actually aligned with Side $\mathrm{A}$ as is indicated by the low calibration index of .0195.

More important, perhaps, is the marginal impact each variable has on j's decision to align with either side. The marginal impact of each of the variables is presented in the final column of Table $1 .{ }^{16}$ This column reports the marginal impact of the unit change in each independent variable specified in column 4 of Table 1, holding the other variables constant at their means if they are continuous variables and modes if they are dichotomous variables. We note first that each of the eight variables has a sizable impact on the probability that $j$ will align with Side A as the value of each variable increases from its observed minimum to its observed maximum. Each variable then is not only statistically significant but substantively significant as well.

Note, however, that the cumulative marginal effects of the variables differ. The cumulative marginal impact of the differences in economic institutions seems to have a greater effect than differences in political institutions on the probability that $\mathrm{j}$ will align with Side A. While the marginal effect of differences in $\mathrm{j}$ 's and Side A's (B's) economic institutions is 53 (49) percent, the marginal effect of differences in j's and Side A's (B's) political institutions is smaller at 37 (39) percent. While the

16 These impacts are calculated based on the coefficients reported in column 2 of Table 1. For detailed discussions of the rationale and procedure see King (1989) and Demaris (1992). 
difference is not large, it is particularly interesting given the considerable attention placed on the importance of regime type by many scholars. Regime type is important-although perhaps in ways not considered by democratic peace theorists-but differences in economic institutions also appear to play a large role in foreign policy decisions. Also note that although the sign of the power variables may be surprising, the cumulative marginal effect on the probability that $j$ will align with Side A as Side A's power increases from .0001 to .82 and Side B's power increases from .00001 to .66, is impressively high, 69 percent and 42 percent, respectively. Perhaps not as surprising, former alliance commitments also increase the likelihood that the aligning state will align with that side. As the proportion of states on Side A (B) with which $\mathrm{j}$ has an alliance increases from 0 to 1 , the probability that $\mathrm{j}$ will align with Side A increases (decreases) by 41 (28) percent. Perhaps more surprising is that the marginal effect of formal alliance ties is generally smaller than the marginal effects of the other variables.

\section{Regime Differences}

Given recent evidence that democratic states have a special relationship with other democratic states (Doyle, 1983, 1986; Siverson and Emmons, 1991; Dixon, 1993, 1994; Maoz and Russett, 1993; Russett, 1993), it is reasonable to wonder whether the results presented in Table 1 are driven solely by the proclivity of democratic states to favor other democracies. The failure to differentiate whether the aligning state is a democracy may mask the possibility that only democratic states behave in this manner and that autocracies do not base their foreign policy decisions on the similarity of state institutions. This concern is alleviated somewhat by the significance of the differences in economic institutions, as democratic peace theorists do not posit that states with similar economic institutions should have a natural affinity for each other. However, confidence in the general effect of institutional similarities, rather than solely democratic bonds, would be increased if alignment decisions were based on the similarity of political and economic institutions regardless of the regime type of the state that must choose.

We can provide such confidence by splitting the data set in two, one part including only democratic aligning states and another including only autocratic aligning states. Aligning states with an institutionalized democracy score of six or above are included in the "democracy" data set while states with an institutionalized democracy score below six are included in the "autocracy" data set. If political similarity is only important to democratic states, then differences in the political institutions of $\mathrm{j}$ and Sides A and B will not be relevant to an autocracy's alignment behavior.

Table 2 reports the results of the logistic regression model for the set of democratic aligning states. The number of cases has been reduced from 385 to 137 . First, the classification table indicates that the model performs very well, correctly predicting 86.13 percent of the cases. This is actually an improvement over the percent predicted correctly when the full data set was analyzed. Second, despite the impressive strength of the model, only the institutional variables retain their expected signs and their significance at traditional levels. Both the power and alliance variables become statistically insignificant and the power variables reverse their signs as well. Several explanations for these changes might be offered. It is possible that the alignment decisions of democracies are only affected by institutional similarities and not by power or by former commitments. This would be very surprising, however, especially with respect to prior alliance commitments. Perhaps more likely, these results might indicate a selection effect similar to that noted by Fearon (1994b). If the allies of democratic states are less likely to be attacked to begin with, presumably because the alliance commitments of democracies are so credible, then the population of alignment opportunities for democratic states has 
TABLE 2. The Effects of Political and Economic Institutional Differences, Power Relations, and Formal Alliance Ties on Democratic Joiners' Decisions to Align with Side A

\begin{tabular}{|c|c|c|c|c|}
\hline Variable & Coefficient & $\begin{array}{l}\text { Standard } \\
\text { Error }\end{array}$ & $\begin{array}{c}\text { Range of } \\
\text { Variable }\end{array}$ & $\begin{array}{l}\text { Change in } \\
\text { Probability } \\
\text { of j Aligning } \\
\text { with Side A }\end{array}$ \\
\hline Constant & -0.3717 & 0.7614 & & \\
\hline Diff. economies of $\mathrm{j} \& \mathrm{~A}$ & -0.4938 & $0.2168^{*}$ & $0-8$ & -.5992 \\
\hline Diff. economies of j \& B & 0.4385 & $0.2015^{*}$ & $0-8$ & .6851 \\
\hline Diff. regime of j \& A & -0.3877 & $0.1031 * * *$ & $0-10$ & -.7418 \\
\hline Diff. regime of j \& B & 0.3645 & $0.1108^{* * *} *$ & $0-10$ & .6869 \\
\hline Power of A & -0.9067 & 2.2500 & $.0006-.7660$ & -.1552 \\
\hline Power of B & 1.4233 & 2.7112 & $.00001-.4726$ & .1648 \\
\hline Defense pact between j \& A & 47.3671 & 211.0514 & $0-1$ & .6002 \\
\hline Defense pact between j \& B & -43.4231 & 211.0423 & $0-1$ & -.3998 \\
\hline
\end{tabular}

$* * *=\mathrm{p} \leq 0.001 ; * *=\mathrm{p} \leq 0.01 ; *=\mathrm{p} \leq 0.05$

Actual Behavior of $\quad$ Predicted Behavior of Joining State

Joining State Join State B Join State A

\begin{tabular}{lrr}
\hline Join State B & 62 & 9 \\
Join State A & 10 & 56
\end{tabular}

Percentage of correct predictions $=86.13 ;$ null model $=51.83 ; \mathrm{N}=137$

Model chi-square $=102.932$, d.f. $=8$, significance $<0.0001$, pseudo $\mathrm{R}^{2}=.74$

Significance levels based on $\mathrm{X}^{2}$ calculations

been biased toward those defense pacts that were initially considered incredible for one reason or another. ${ }^{17}$ If so, it is not surprising that formal alliance commitments do not anticipate well the alignment choices of democratic states.

Although we are quite willing to be instructed on this point, we do not foresee how a similar selection effect could operate with respect to the power variables. As a result, although we hesitate to draw conclusions regarding the alliance variables, the data seem to suggest that the alignment decisions of democratic states do not depend on the power of the disputants. Instead, democratic states choose to align with the side that shares similar political and economic institutions. As would be expected from the normative argument of the democratic peace, democracies do seem to share a special relationship with other democracies. Note, however, that democratic peace theory does not explain why economic similarity would matter, as it apparently does.

The last column of Table 2 reports the marginal impact of each of the variables. We only discuss the substantive significance of the institutional variables as they are the only factors that systematically affect a democracy's alignment behavior. The marginal impact of these variables remains formidable, and in fact, increases from those reported in Table 3 . The probability that a democratic state will align with

\footnotetext{
${ }^{17}$ Gartner and Siverson (1996) argue that multilateral wars are uncommon because state leaders intentionally select targets that are unlikely to inspire intervention by a third party. A defense pact with a democratic state might be a clear indication to potential aggressors that an attack on such a target will not prove fruitful.
} 
Side A decreases by 59 and 74 percent as its economic and political institutions range from being very similar to being very dissimilar to those of Side A. Likewise, the probability that a democratic state will align with Side A increases by 68 percent as both its economic and political institutions range from being very similar to being very dissimilar to those of Side B.

The real test, however, is whether the institutional variables remain important when only the autocratic aligning states are considered. Table 3 reports the same logistic regression model including only autocratic aligning states. Despite the exclusion of the democratic aligning states, the institutional variables, as well as the power and alliance variables, retain the expected sign and are statistically significant. Autocratic aligning states, like democratic aligning states, also consider the similarities and differences in the political and economic institutions of each side in their alignment decisions. This evidence suggests, at a minimum, that democratic states alone do not share a special relationship. It also provides support for both the psychological and interest-based explanations which argue that differences in institutions motivate foreign policy behavior as they indicate which states in the system are threatening. Although the fit of the model is not quite as impressive as that reported for democratic aligning states (the percent predicted correctly decreases to 74.19 percent), it is still quite good. The final column of Table 3 also indicates that the institutional variables remain substantively significant. Although their marginal effect is less than that for democratic aligning states, the likelihood that an autocratic state will align with Side A is changed significantly as the states' institutions become more and less similar to those of Sides A and B.

Table 3. The Effects of Political and Economic Institutional Differences, Power Relations, and Formal Alliance Ties on Authoritarian Joiners' Decisions to Align with Side A

\begin{tabular}{|c|c|c|c|c|}
\hline Variable & Coefficient & $\begin{array}{l}\text { Standard } \\
\text { Error }\end{array}$ & $\begin{array}{l}\text { Range of } \\
\text { Variable }\end{array}$ & $\begin{array}{l}\text { Change in } \\
\text { Probability } \\
\text { of } j \text { Aligning } \\
\text { with Side A }\end{array}$ \\
\hline Constant & -0.4862 & 0.3456 & & \\
\hline Diff. economies of $\mathrm{j} \& \mathrm{~A}$ & -0.3084 & $0.0868 * * *$ & $0-8$ & -.4928 \\
\hline Diff. economies of $\mathrm{j} \& \mathrm{~B}$ & 0.2282 & $0.0906 * *$ & $0-8$ & .4191 \\
\hline Diff. regime of $\mathrm{j} \& \mathrm{~A}$ & -0.1302 & $0.0628 *$ & $0-10$ & -.2998 \\
\hline Diff. regime of $\mathrm{j} \& \mathrm{~B}$ & 0.1913 & $0.0750 * *$ & $0-10$ & .4357 \\
\hline Power of A & 8.1567 & $1.7849 * * *$ & $.0001-.8216$ & .7244 \\
\hline Power of B & -4.3353 & $1.3733^{* *}$ & $.00001-.6653$ & -.4982 \\
\hline Defense pact between $\mathrm{j} \& \mathrm{~A}$ & 1.6546 & $0.4978 * * *$ & $0-1$ & .3574 \\
\hline Defense pact between j \& B & -1.1828 & $0.5648^{*}$ & $0-1$ & -.2524 \\
\hline \multicolumn{5}{|c|}{$* * *=\mathrm{p} \leq 0.001 ; * *=\mathrm{p} \leq 0.01 ; *=\mathrm{p} \leq 0.05$} \\
\hline \multicolumn{5}{|c|}{ Predicted Behavior of Joining State } \\
\hline $\begin{array}{l}\text { Actual Behavior of } \\
\text { Joining State }\end{array}$ & Join State B & Join Stat & & \\
\hline Join State B & 93 & 28 & & \\
\hline Join State A & 36 & 91 & & \\
\hline
\end{tabular}

Percentage of correct predictions $=74.19 ;$ null model $=51.21 ; \mathrm{N}=248$

Model chi-square $=91.998$, d.f. $=8$, significance $<0.0001$, pseudo $\mathrm{R}^{2}=.47$

Significance levels based on $\mathrm{X}^{2}$ calculations 
While the institutional variables retain their statistical and substantive importance in both parts of our data set, it is interesting that the relevance of the power variables differs dramatically depending upon whether the aligning state is democratic or autocratic. As noted above, the power of Sides A and B have little effect on a democratic state's decision to align with either side. In contrast, the power of Sides $\mathrm{A}$ and $\mathrm{B}$ matter quite a bit to an autocracy. The probability that an autocracy will align with Side A increases by 72 percent and decreases by 49 percent as the power of Side A and Side B, respectively, increase from their observed minimums to their observed maximums. Although institutions matter to autocracies, so too does power. While none of the literature reviewed provides any insight into this difference, it seems an extremely interesting puzzle for further research.

Note also that the data clearly suggest that formal alliance commitments do affect the alignment decisions of autocracies. This obvious change from the results reported for democratic aligning states suggests either that the alliance commitments made by autocracies do not produce the same selection effects noted for defense pacts involving democratic aligning states, or simply that autocracies are more likely to honor their formal commitments than are democracies. Either way, the difference between the data sets is extremely interesting. In the first case, if the degree to which a selection effect operates varies for democracies and autocracies, then states that attack the allies of democratic and autocratic states must view the threat posed by these alliance commitments differently. This is especially puzzling because it appears that autocratic aligning states do base their alignment choices on their prior commitments. In the second case, if autocracies are more likely to honor their commitments than are democracies, then we might rethink the increasingly popular assumption that democracies endure greater audience, or back-down, costs than do autocracies (Fearon, 1994a).

\section{Temporal Differences}

As a final evaluation of the relevance and strength of these alternate explanations for alignment behavior, we consider the impact of a temporal control. While there is little reason to expect that the impact of power and formal commitments will change over time, it is likely that the effect of domestic institutions might vary. In particular, the psychological and interest-based explanations suggest only that institutional differences are important because they affect a leader's perception of the threat posed by others in the international system. Neither argument, however, suggests which domestic institutions will be particularly relevant. The indicators of institutional differences chosen for this study are clearly indicative of those features considered particularly salient in the present. However, there is no reason to expect that regime type and government economic involvement are necessarily the most salient institutional differences across all periods of time. The key determinants of ingroups and outgroups and resource distribution might very well depend on other types of institutions. Since neither approach offers a theory about which institutional differences will pose a threat to the leader and thus become salient to foreign policy decision making, it is reasonable to expect that the relevance of the institutional variables might vary across time. ${ }^{18}$

As a preliminary check to determine whether the relevance of the institutional variables to alignment behavior varies across time, we separate the data into two time periods-the nineteenth and twentieth centuries. Other scholars have found

\footnotetext{
18 Such a theory might focus particularly on those institutions that vary the most across states in the international system. In addition, the interest-based argument would also consider which institutions have the greatest distributional consequences within a society.
} 
inter-century differences in their results, making this dividing point particularly telling (Singer, Bremer, and Stuckey, 1972). As Table 4 reveals, there are sharp variations in the significance of these particular institutional variables across time. In the twentieth century, differences in the political and economic institutions of the states were very important to alignment behavior. In the nineteenth century, in contrast, differences in these institutions appear irrelevant. Surprisingly, the power and alliance variables do not perform well in the nineteenth century either. Although this might not be surprising given that there were only 76 instances of alignment in the nineteenth century, compared to 309 cases in the twentieth century, the insignificance of almost all of the variables suggests that there are important differences between the centuries which we have yet to identify.

TABle 4. The Effects of Political and Economic Institutional Differences, Power Relations, and Formal Alliance Ties on a Joiner's Decision to Align with Side (19th and 20th Centuries)

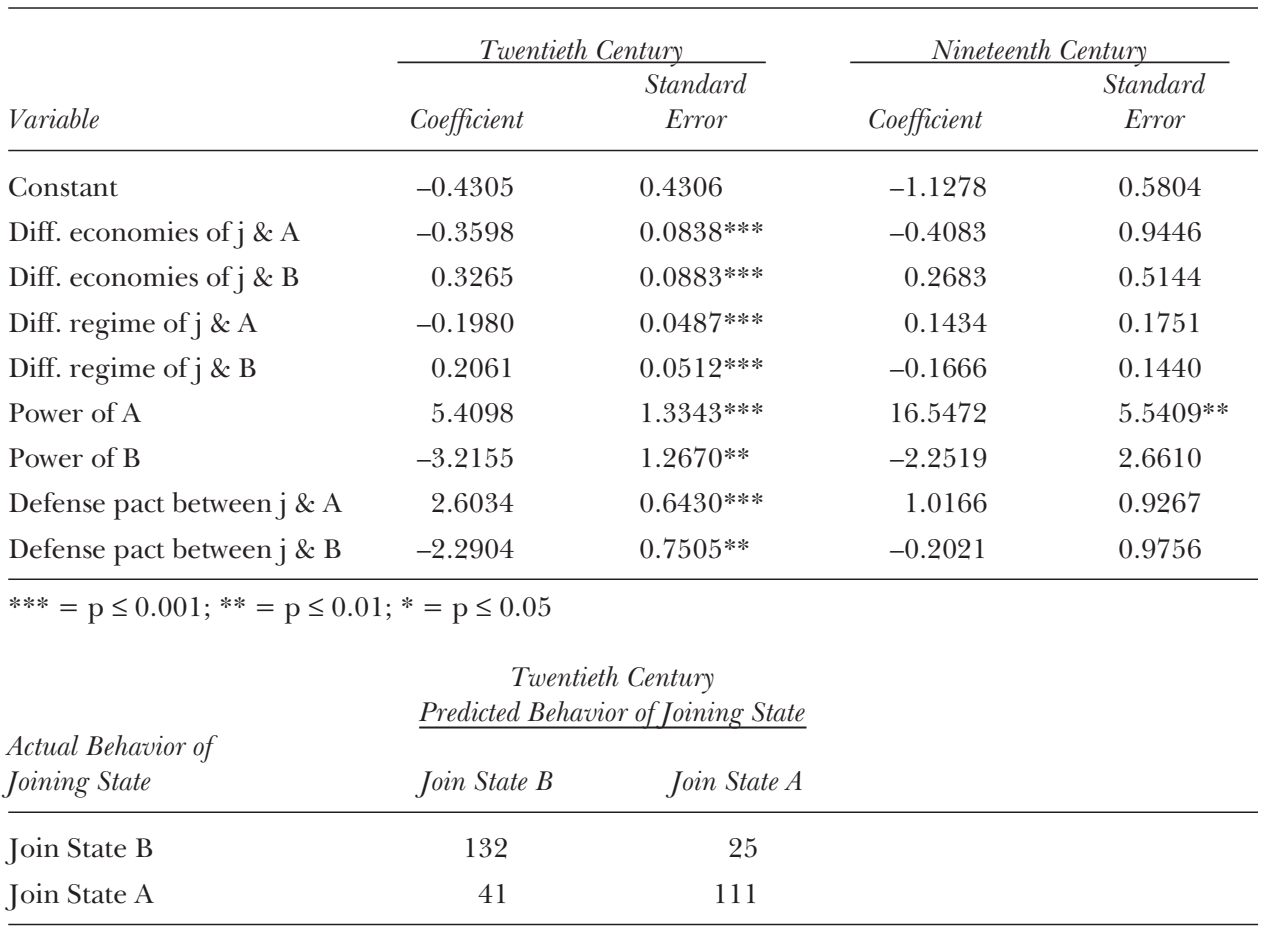

Percentage of correct predictions $=78.64 ;$ null model $=50.81 ; \mathrm{N}=309$

Model chi-square $=160.806$, d.f. $=8$, significance $<0.0001$, pseudo $\mathrm{R}^{2}=.59$

Significance levels based on $\mathrm{X}^{2}$ calculations

\begin{tabular}{lcc} 
& \multicolumn{2}{c}{$\begin{array}{c}\text { Nineteenth Century } \\
\text { Actual Behavior of }\end{array}$} \\
\cline { 2 - 3 } Joining State & Join State B & Join State A \\
\hline Join State B & 27 & 8 \\
Join State A & 10 & 31 \\
\hline
\end{tabular}

Percentage of correct predictions $=76.32 ;$ null model $=53.95 ; \mathrm{N}=76$

Model chi-square $=27.681$, d.f. $=8$, significance $<0.0005$, pseudo $\mathrm{R}^{2}=.46$

Significance levels based on $\mathrm{X}^{2}$ calculations 
One possibility suggests itself at least with respect to the institutional variables. We might, of course, conclude that the significance of domestic institutions to the alignment choices of states is merely a twentieth-century phenomenon, perhaps a product of the Cold War and the sharp ideological divide in World War II. Although these particular domestic institutions appear irrelevant to alignment choices in the nineteenth century, it is perhaps overly hasty to discount the relevance of differences in all domestic institutions. This is especially true if we return to the original idea posited by Hermann and Kegley (1995) and Werner and Lemke (1996) that it must be differences in institutional structures that affect perceptions of threat. Closer inspection of the data reveals that there was little variation in the political and economic domestic structures of the states included in this data set for the nineteenth century. ${ }^{19}$ Differences in these particular domestic institutions then did not matter to nineteenth-century alignment choices, because there were few differences during that time. In order to explain alignment choices through time, it will be necessary to develop more advanced expectations of which domestic institutions will be particularly salient. The most obvious place to begin is to identify the types of institutions over which states differed at any particular period of time.

\section{Implications and Conclusions}

The empirical evidence advanced in this article suggests that a relationship exists between alignment behavior in international disputes and differences in political and economic institutions. This relationship has been absent from previous studies on conflict expansion. Importantly, this relationship persists regardless of whether the aligning state is democratic or autocratic. The empirical evidence also suggests that the power of each disputing side is important to some aligning states, but not to others. In particular, autocratic aligning states are far more likely to align with a side as its power grows, whereas democratic aligning states are not systematically influenced by power considerations. Finally, the data provide confounding information regarding the effect of alliance commitments on alignment behavior. Whereas the alignment choices of democracies are not affected by alliance commitments, such promises do affect autocratic alignment behavior. The potential for selection effects was noted.

These empirical findings are important because they suggest new avenues of exploration for those interested in the potentially related question of the democratic peace. With a few exceptions (Maoz and Abdolali, 1989; Weart, 1994; Leeds and Davis, 1995), most scholars have found that only democratic states share a special relationship, leading them to focus on characteristics unique to democracies like democratic norms or institutional constraints. However, if autocracies also favor

\footnotetext{
${ }^{19}$ In the twentieth century, differences on the scope variable ranged from zero, suggesting very similar economic structures, to eight, suggesting large differences in economic institutions. In contrast, in the nineteenth century for the states included in this data set, the largest difference between the scope scores was two, suggesting that during this time government involvement in the economy was minimal for most states. The mean of the variable measuring differences in the economy of $\mathrm{j}$ and Side A ( $\mathrm{j}$ and Side B) was 2.37 (3.90) with a standard deviation of 1.97 (1.81) in the twentieth century, compared to a mean of $.18(.41)$ and standard deviation of $.38(.70)$ in the nineteenth century. As one would expect, there is also substantial differences in the variation of the institutionalized democracy variable across the nineteenth and twentieth centuries. In the nineteenth century, in over 60 percent of the cases, the difference between the institutionalized democracy score of the aligning state and one of the original disputants was less than two. In contrast, in the twentieth century, less than 40 percent of the cases had such a small difference in their scores. Additionally, in the nineteenth century less than 2 percent of the cases were ones in which the aligning state and the original disputants' institutionalized democracy scores differed by eight or more. In the twentieth century, approximately 20 percent of the cases involved such large differences. The mean of the variable measuring differences in the polity of $\mathrm{j}$ and Side A ( $\mathrm{j}$ and Side B) was 3.97 (3.90) with a standard deviation of 3.57 (3.33) in the twentieth century, compared to a mean of 2.45 (2.31) and standard deviation of 2.25 (2.49) in the nineteenth century.
} 
each other, then the exclusive focus on democratic institutions and norms may be overly narrow. Likewise, the importance of economic similarity also suggests that an exclusive focus on regime type is unwarranted. While democracies may be unique, as is possibly indicated by their failure to base alignment choices on power considerations, other domestic attributes also matter to foreign policy decision making.

Given the consistent empirical evidence that differences in domestic institutions affect alignment behavior, additional theoretical development seems necessary. Potentially fruitful avenues are suggested by both the psychological argument of Hermann and Kegley (1995) and the interest-based argument of Werner and Lemke (1996). Both approaches posit that differences in domestic institutions are important because they indicate the degree to which other states pose a threat to the state or its leader. These arguments differ significantly from both realist and neorealist expectations that domestic attributes are irrelevant to power politics and traditional liberal expectations which focus on variation in either the institutional constraints or the norms created by different types of regimes. If differences in domestic institutions affect perceptions of threat, then domestic institutions are central to security issues.

These empirical findings are also important because they suggest that the conventional realist and neorealist expectations of alignment behavior should be reconsidered. The basic assumptions of realism imply that states with greater power should pose a threat to weaker states. Concerned with their security, weaker states should balance against this threat to prevent their elimination. The data indicate, however, that states do not tend to align themselves with the weaker state but rather tend to bandwagon with the stronger side. While this bandwagoning effect accords with some revisionist realist expectations (Kaufman, 1992; Schweller, 1994), the predominance of bandwagoning definitely raises doubts about the fundamental expectations of realist thought. If states rarely balance, perhaps it is the case that they do not necessarily find power threatening. Furthermore, the conventional wisdom is squarely challenged by the fact that democratic states do not appear to weigh power considerations in their alignment choices at all-they neither balance nor bandwagon. Power concerns then are not universal. Rather, the degree to which power plays into foreign policy decision making depends on the internal attributes of the states considered.

Finally, the mixed effect of prior alliance commitments on alignment behavior raises several interesting puzzles. Initially, the expectation that previous commitments to offer aid in the event of an attack should provide the clearest indicator of a state's alignment behavior appears extremely sound, if not obvious. It was quite surprising then for the data to suggest that only autocracies base their alignment behavior on prior alliance commitments. We suggested that the null results for democratic states might actually suggest that such prior commitments are so credible that a selection effect is created. While this seems plausible, the puzzle still remains because the significant relationship between prior commitments and alignment behavior for autocracies suggests that such a selection effect is not operating for these defense pacts, even though autocracies do appear to base their alignment behavior on their alliance commitments. Exploration of this variation is an interesting area for future research.

There are important limitations which must be noted and extensions and modifications which must still be made. We have already noted that these results must be interpreted with caution as a result of possible selection effects. The inter-temporal differences also create some doubt as to the generalizability of these findings. Clearly, in order to determine whether institutional differences affect alignment behavior generally, additional work is necessary to explain which institutional differences may be particularly relevant at any time to a leader or a state. 
While there are obvious areas for development and improvement, the empirical evidence presented here suggests an interesting picture of international interactions and the relevance particularly of national-level factors to those interactions. Empirical analysis increases our confidence that differences in domestic institutions and, under some conditions, power and alliance commitments, have a significant impact on foreign policy decisions.

\section{References}

Aldrich, J. H., ANd F. D. Nelson (1984) Linear Probability, Logit, and Probit Models. Sage University Paper Series on Quantitative Applications in the Social Sciences, series no. 07-045. Newbury Park, CA: Sage.

Altfeld, M. F., And B. Bueno de Mesquita (1979) Choosing Sides in Wars. International Studies Quarterly 23:87-112.

Bremer, S. (1982) The Contagiousness of Coercion: The Spread of Serious International Disputes, 1900-1976. International Interactions 9:29-55.

Bueno de Mesquita, B., R. M. Siverson, and G. Woller (1992) War and the Fate of Regimes. American Political Science Review 86:638-646.

Bueno de Mesquita, B., And R. M. Siverson (1995) War and the Survival of Political Leaders: A Comparative Study of Regime Types and Political Accountability. American Political Science Review 89:841-855.

Davis, W. W., G. T. Duncan, AND R. M. Siverson (1978) The Dynamics of Warfare, 1816-1965. American Journal of Political Science 22:772-792.

Demaris, A. (1992) Logit Modeling: Practical Applications. Sage University Paper Series on Quantitative Applications in the Social Sciences, series no. 07-086. Newbury Park, CA: Sage.

Dixon, W. J. (1993) Democracy and the Management of International Conflict. Journal of Conflict Resolution 37:42-68.

Dixon, W. J. (1994) Democracy and the Peaceful Settlement of International Conflict. American Political Science Review 88:14-32.

Doyle, M. (1983) Kant, Liberal Legacies, and Foreign Affairs, Part I. Philosophy and Public Affairs 12:205-235.

Doyle, M. (1986) Liberalism and World Politics. American Political Science Review 80:115-161.

FEAron, J. D. (1994a) Domestic Political Audiences and the Escalation of International Disputes. American Political Science Review 88:577-592.

FEARON, J. D. (1994b) Signaling Versus the Balance of Power and Interests: An Empirical Test of a Crisis Bargaining Model. Journal of Conflict Resolution 38:236-270.

GARTNER, S. S., AND R. M. Siverson (1996) War Expansion and War Outcome. Journal of Conflict Resolution 40:4-15.

Gochman, C. S., And Z. MaOz (1984) Militarized Interstate Disputes, 1816-1976. Journal of Conflict Resolution 28:585-616.

Grieco, J. (1988) Anarchy and the Limits of Cooperation. International Organization 42:485-507.

Gurr, T. R., K. Jaggers, ANd W. Moore (1989) Polity II Codebook. Boulder, CO: Center for Comparative Politics, Department of Political Science, University of Colorado.

Gurr, T. R., K. Jaggers, and W. Moore (1990) The Transformation of the Western State. Studies in Comparative International Development 25:73-108.

Hagle, T. M., And G. E. Mitchell, II (1992) Goodness-of-Fit Measures for Probit and Logit. American Journal of Political Science 36:762-784.

Hermann, M. G., and C. W. Kegley, Jr. (1995) Rethinking Democracy and International Peace: Perspectives from Political Psychology. International Studies Quarterly 39:511-534.

Huntington, S. P. (1991) The Third Wave: Democratization in the Late Twentieth Century. Norman: University of Oklahoma Press.

JAGGERS, K. (1992) War and the Three Faces of Power: War Making and State Making in Europe and the Americas. Comparative Political Studies 25:26-62.

Kaufman, R. G. (1992) To Balance or to Bandwagon? Alignment Decisions in 1930s Europe. Security Studies 1:417-447.

Kegley, C. W., And G. A. Raymond (1990) When Trust Breaks Down. Columbia: University of South Carolina Press.

KING, G. (1989) Unifying Political Methodology. New York: Cambridge University Press. 
Knight, J. (1992) Institutions and Social Conflict. New York: Cambridge University Press.

Lake, D. A. (1992) Powerful Pacifists: Democratic States and War. American Political Science Review 86:24-37.

LAKE, D. A. (1996) Anarchy, Hierarchy, and the Variety of International Relations. International Organization 50:1-33.

Leeds, B. A., AND D. Davis (1995) Beneath the Surface: The Democratic Peace and Beyond. Manuscript.

Levy, J. (1982) The Contagion of Great Power War Behavior, 1495-1975. American Journal of Political Science 26:562-584.

LEvY, J. (1989) “The Diversionary Theory of War.” In Handbook of War Studies, edited by M. Midlarsky, pp. 259-288. Boston: Unwin Hyman.

Lutz, J. M. (1989) The Diffusion of Political Phenomena in Sub-Saharan Africa. Journal of Political and Military Sociology 17:93-114.

MaOz, Z., AND N. Abdolali (1989) Regime Types and International Conflict. Journal of Conflict Resolution 33:3-35.

Maoz, Z., ANd B. RussetT (1993) Normative and Structural Causes of Democratic Peace: 1946-1986. American Political Science Review 87:624-638.

Morgan, T. C., AND K. N. Bickers (1992) Domestic Discontent and the External Use of Force. Journal of Conflict Resolution 36:25-52.

Morgenthau, H. J. (1948) Politics Among Nations. New York: Alfred A. Knopf.

Most, B. A., AND H. STARR (1980) Diffusion, Reinforcement, Geopolitics, and the Spread of War. American Political Science Review 74:932-946.

NorTH, D. C. (1981) Structure and Change in Economic History. New York: W. W. Norton.

RAY, J. L. (1989) The Abolition of Slavery and the End of International War. International Organization 43:405-439.

Russett, B. (1993) Grasping the Democratic Peace. Princeton, NJ: Princeton University Press.

Schweller, R. L. (1994) Bandwagoning for Profit: Bringing the Revisionist State Back In. International Security 19:72-107.

Singer, J. D., S. Bremer, And J. Stuckey (1972) "Capability Distribution, Uncertainty, and Major Power War, 1816-1965." In Peace, War and Numbers, edited by B. Russett, pp. 19-48. Beverly Hills: Sage.

Singer, J. D., ANd M. Small (1966) Formal Alliances, 1816-1939: A Quantitative Description. Journal of Peace Research 3:1-32.

Siverson, R. M., AND J. Emmons (1991) Birds of a Feather. Journal of Conflict Resolution 35:285-306.

Siverson, R. M., AND J. King (1979) “Alliances and the Expansion of War.” In To Auger Well: Early Warning Indicators in World Politics, edited by J. D. Singer and M. D. Wallace. Beverly Hills: Sage.

Siverson, R. M., AND H. Starr (1990) Opportunity, Willingness, and the Diffusion of War. American Political Science Review 84:47-67.

Siverson, R. M., And H. Starr (1991) The Diffusion of War: A Study of Opportunity and Willingness. Ann Arbor: University of Michigan Press.

Small, M., AND J. D. Singer (1969) Formal Alliances, 1816-1965: An Extension of the Basic Data.Journal of Peace Research 3:257-282.

Starr, H. (1991) Democratic Dominoes: Diffusion Approaches to the Spread of Democracy. Journal of Conflict Resolution 35:356-381.

Walt, S. M. (1987) The Origins of Alliances. Ithaca, NY: Cornell University Press.

WaLTZ, K. N. (1979) Theory of International Politics. New York: McGraw-Hill.

Waltz, K. N. (1986) "Reflections on Theory of International Politics." In Neorealism and Its Critics, edited by R. O. Keohane, pp. 322-346. New York: Columbia University Press.

Weart, S. R. (1994) Peace Among Democratic and Oligarchic Republics. Journal of Peace Research 31:299-316.

Werner, S. (1996) Absolute and Limited War: The Possibility of Foreign-Imposed Regime Change. International Interactions 22:67-88.

Werner, S., And D. Lemke (1996) Systemic Effects on Dyadic Relations: The Incentive to Use Force. Manuscript.

Yamamoto, Y., And S. A. Bremer (1980) "Wider Wars and Restless Nights: Major Power Intervention in Ongoing War." In The Correlates of War: II. Testing Some Realpolitik Models, edited by J. D. Singer, pp. 199-232. New York: Free Press.

Yates, J. F. (1990) Judgment and Decision Making. Englewood Cliffs, NJ: Prentice Hall. 